\title{
ARTICLE
}

\section{MICROSTRUCTURE AND PHASE TRANSFORMATION OF Ni-Ti-Fe-Nd QUATERNARY SHAPE MEMORY ALLOY}

Dovchinvanchig M.*

\author{
Department of Mathematics, Physics and Information Technology \\ School of Engineering and Technology, Mongolian University of Life Sciences \\ Ulaanbaatar, Mongolia
}

ARTICLE INFO: Received: 19 Oct, 2018; Accepted: 21 Apr, 2019

\begin{abstract}
The effect of rare earth element neodymium (Nd) addition on the microstructure and phase transformation behavior of $\mathrm{Ni}_{50} \mathrm{Ti}_{47} \mathrm{Fe}_{2} \mathrm{Nd}_{1}$ shape memory alloy was investigated by scanning electronic microscope, $X$-ray diffraction and differential scanning calorimetry. The results show that the microstructure of $\mathrm{Ni}$-Ti-Fe-Nd quaternary alloy consists of $\mathrm{NiNd}_{3}$ phase, $\mathrm{NiTi}_{2}$ and the NiTi matrix. A one-step martensitic transformation is observed in the alloys. The martensitic transformation start temperature $M s 54.11^{\circ} \mathrm{C}$.
\end{abstract}

Keywords: Ni-Ti-Fe-Nd quaternary shape memory alloy; Microstructure; Phase transformation;

\section{INTRODUCTION}

Ni-Ti based shape memory alloys are technologically important materials because of their unique shape memory effect and super elastic behavior and they have been used in various fields, particularly in engineering and medical application [1]. The current research interest on SMA is primarily on controlling the martensitic transformation temperature and improving the shape memory effect for their application.

The effect of martensitic transformation, super-elasticity and shape memory effect have been studied widely by adding transitional elements to Ni-Ti binary alloys which include $\mathrm{Fe}, \mathrm{Hf}, \mathrm{Zr}$, Pd, Pt, etc. Among them, Fe and
$\mathrm{Nb}$ have been added to Ni-Ti binary alloys, which decrease the martensitic transformation temperature, but $\mathrm{Hf}, \mathrm{Zr}, \mathrm{Pd}$ and $\mathrm{Pt}$ addition can increase the martensitic transformation temperature of Ni-Ti alloys.

Moreover, the microstructure and martensitic transformation temperature of the Ni-Ti binary alloys have also been studied using scanning electron microscopy (SEM), energy dispersive spectrometry (EDS), X-ray diffraction (XRD), and differential scanning calorimetry (DSC). The Ni-Ti binary alloys were found to decrease and increase the phase transformation temperature and change the phase transformation sequence. 
Rare earth element $\mathrm{Nd}$ is also a widely used element, particularly in magnetic materials. However, only few studies have been conducted on $\mathrm{Nd}$ addition to shape memory alloy. The only study found in the literature is that on $\mathrm{Nd}$ addition to $\mathrm{Ti}_{50} \mathrm{Ni}_{47} \mathrm{Fe}_{2.5} \mathrm{Nd}_{0.5}$ alloy

\section{MATERIALS AND METHODS}

The $\mathrm{Ni}_{50} \mathrm{Ti}_{47} \mathrm{Fe}_{2} \mathrm{Nd}_{1}$ quaternary alloy was prepared by melting $50 \mathrm{~g}$ of raw materials with different nominal compositions (99.99 mass \% sponge Ti, 99.99 mass \% electrolytic Ni, 99.99 mass \% Fe and 99.95 mass \% Nd) in a non-consumable arc-melting furnace using a water-cooled copper crucible. Arc-melting was repeated four times to ensure the uniformity of the composition. The specimens are sparkcut from the ingots and solution-treated at $850^{\circ} \mathrm{C}$ for one hour in a quartz tube furnace. Subsequently, the specimens were quenched using water. Thereafter, the specimens were
[2]. The effect of Nd addition to Ni-Ti-Fe ternary alloy on microstructure and martensite transformation temperature remains unclear. In this paper, $\mathrm{Ni}_{50} \mathrm{Ti}_{47} \mathrm{Fe}_{2} \mathrm{Nd}_{1}$ quaternary alloys, and the microstructure and phase transformation were studied experimentally.

\section{RESULTS AND DISCUSSION}

Microstructure of $\mathrm{Ni}_{50} \mathrm{Ti}_{47} \mathrm{Fe}_{2} \mathrm{Nd}_{1}$ alloy

Figure 1 depicts the XRD pattern of $\mathrm{Ni}_{50} \mathrm{Ti}_{47} \mathrm{Fe}_{2} \mathrm{Nd}_{1}$ alloy at room temperature. The diffraction peak can be attributed to NiTi B2 parent phase, a $\mathrm{NiTi}_{2}$ phase and a $\mathrm{NiNd}_{3}$ phase after comparison with the corresponding mechanically and lightly polished to obtain a plain surface.

The phase transformation temperatures of $\mathrm{Ni}_{50} \mathrm{Ti}_{47} \mathrm{Fe}_{2} \mathrm{Nd}_{1}$ alloys were determined by differential scanning calorimeter (DSC) using a Perkin-Elmer Diamond calorimeter. The temperature range of heating and cooling was from $-30^{\circ} \mathrm{C}$ to $150^{\circ} \mathrm{C}$, and the scanning rate of heating and cooling was $10^{\circ} \mathrm{C} / \mathrm{min}$. SEM observations were conducted using a S-3400N Hitachi with EDS analysis systems made by Oxford. An XRD experiment was conducted using a D/MAX-2500PC X-ray diffractometer.

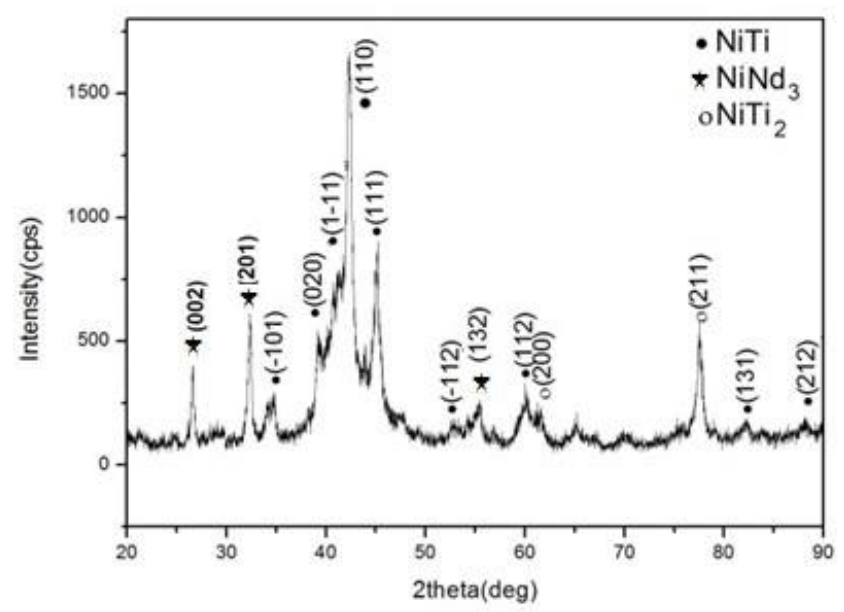

Figure 1. XRD pattern of Ni50Ti47Fe2Nd1 alloys 
The lattice parameter of alloy can be also calculated [3] by peak position in XRD pattern which shown in Table 1.

Table 1. Lattice parameters of $\mathrm{Ni}-\mathrm{Ti}-\mathrm{Fe}-\mathrm{Nd}$ alloys

\begin{tabular}{|c|c|c|c|c|}
\hline Alloy & Phase & $a(\mathrm{~nm})$ & $V\left(\mathrm{~nm}^{3}\right)$ & Source \\
\hline Ni-Ti-Fe-Nd & $\mathrm{P}$ & 0.3035 & 0.02795 & This work \\
\hline $\mathrm{NiTi}$ & $\mathrm{P}$ & 0.3007 & 0.02719 & JCPDF card No.65-4572 \\
\hline $\mathrm{NiTi}_{2}$ & & 1.131 & 1.4503 & JCPDF card No.72-0442 \\
\hline $\mathrm{NiNd}_{3}$ & & 0.3803 & 0.17262 & JCPDF card No.19-0818 \\
\hline
\end{tabular}

\section{Morphologies and compositions of} $\mathrm{Ni} \mathrm{i}_{50} \mathrm{Ti}_{47} \mathrm{Fe}_{2} \mathrm{Nd}$ alloy

Figure 2 depicts the back-scattering SEM images of $\mathrm{Ni}_{50} \mathrm{Ti}_{47} \mathrm{Fe}_{2} \mathrm{Nd}_{1}$ alloy. Three different morphologies, namely, white phase, black phase and matrix, can be identified in the SEM image (Figure 2). Some white particles that are nearly round-shape and up to $5 \mu \mathrm{m}$ in diameter respectively with white curving areas can be found to be distributed randomly in the matrix. The black phase is distributed randomly in the matrix.

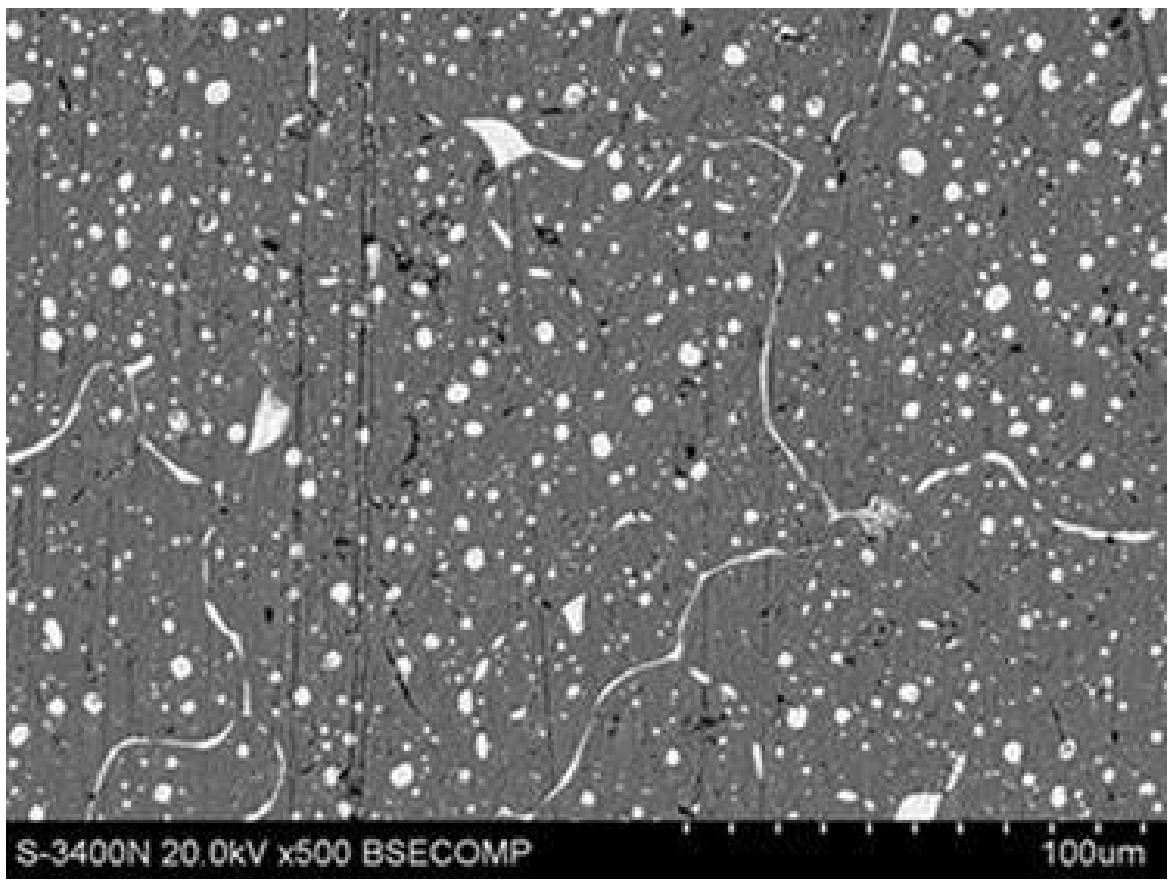

Figure 2. Back-scattering SEM images of Ni-Ti-Fe-Nd alloys

To identify the phase structure, EDS analysis was conducted in SEM. The compositions of $\mathrm{Ni}_{50} \mathrm{Ti}_{47} \mathrm{Fe}_{2} \mathrm{Nd}_{1}$ alloy are shown in Table 2. The Ti:Ni ratio in the matrix of $\mathrm{Ni}-\mathrm{Ti}-\mathrm{Fe}-\mathrm{Nd}$ alloy is measured to be close to 1 and with a small amount of Fe solid solute. The Ti:Ni ratio in the white phase of Ni-Ti-Fe-
$\mathrm{Nd}$ alloy is measured to be close to $2: 1$. By $\mathrm{XRD}$ analysis, there is an $\mathrm{NiTi}_{2}$ phase . Thus, the black phase can be concluded to be $\mathrm{NiNd}_{3}$ phase. According to the $773 \mathrm{~K}$ isothermal section of the ternary alloy phase diagram of the Ni-Ti-Nd, no intermetallic compounds can be found in the Ti-Nd binary system. However, $-40-$ 
Ni-Nd binary alloy phase diagram shows seven kinds of intermetallic compounds defined as $\mathrm{NdNi}_{5}, \mathrm{Nd}_{2} \mathrm{Ni}_{7}, \mathrm{NdNi}_{3}, \mathrm{NdNi}_{2}, \mathrm{NdNi}, \mathrm{Nd}_{7} \mathrm{Ni}_{13}$, and $\mathrm{Nd}_{3} \mathrm{Ni}$ [4]. The EDS results show that the
$\mathrm{Ni}$ Nd ratio in the white phase is close to $1: 3$ and can be regarded as the $\mathrm{NiNd}_{3}$ intermetallic compound with a small amount of $\mathrm{Ti}$ and $\mathrm{Fe}$ solid solute.

Table 2. Compositions of $\mathrm{Ni}-\mathrm{Ti}-\mathrm{Fe}-\mathrm{Nd}$ alloys

\begin{tabular}{|l|r|r|r|r|}
\hline \multicolumn{1}{|c|}{ Phase } & \multicolumn{1}{c|}{$\mathrm{Ni}($ at \%) } & \multicolumn{1}{c|}{$\mathrm{Ti}($ at \%) } & \multicolumn{1}{c|}{$\mathrm{Fe}($ at \%) } & \multicolumn{1}{c|}{$\mathrm{Nd}($ at \%) } \\
\hline matrix & 49.10 & 49.07 & 1.82 & 0.01 \\
\hline white phase & 33.35 & 65.11 & 1.54 & 0 \\
\hline Black phase & 24.58 & 1.32 & 0.89 & 73.21 \\
\hline
\end{tabular}

Phase transformation of $\mathrm{Ni}_{50} \mathrm{Ti}_{47} \mathrm{Fe}_{2} \mathrm{Nd}$ alloys

Figure 3 depicts the DSC curve of the $\mathrm{Ni}_{50} \mathrm{Ti}_{47} \mathrm{Fe}_{2} \mathrm{Nd}_{1}$ alloy. Each DSC curve shown in one peak during the heating and cooling process, which indicates a one-step B2 $\leftrightarrow$ B19' phase transformation. Cooling process in martensitic start temperature $\mathrm{Ms}=54.110 \mathrm{C}$ and martensitic finish temperatue $\mathrm{M}_{\mathrm{f}}=3.50 \mathrm{C}$, heating process in austenitic start temperature $\mathrm{As}=27.050 \mathrm{C}$ and austenitic finish temperature $\mathrm{A}_{\mathrm{f}}=83.50 \mathrm{C}$.

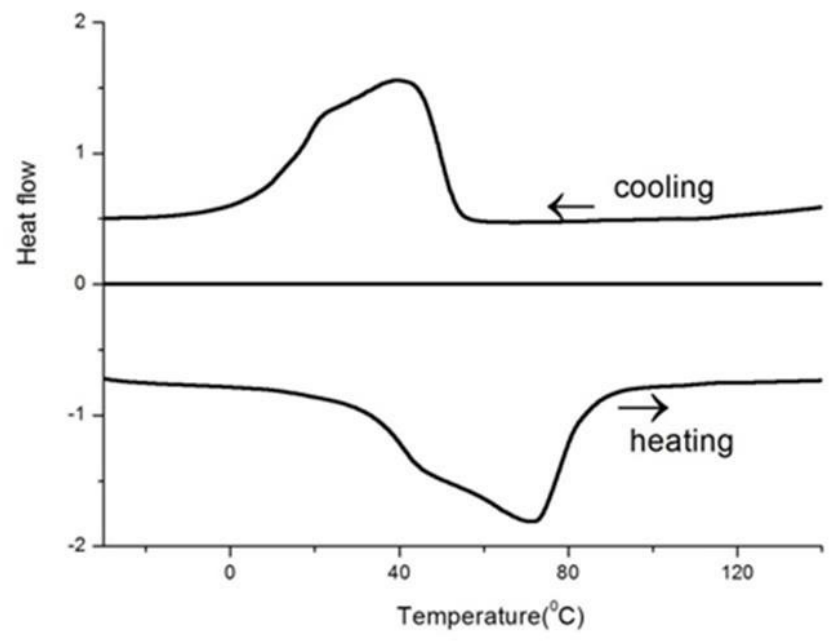

Figure 3. DSC curve of $\mathrm{Ni}-\mathrm{Ti}-\mathrm{Fe}-\mathrm{Nd}$ alloy

\section{CONCLUSIONS}

The microstructure and phase transformation Ni-Ti-Fe-Nd shape memory alloy is investigated. The following conclusions can be drawn. The $\mathrm{Ni}_{50} \mathrm{Ti}_{47} \mathrm{Fe}_{2} \mathrm{Nd}_{1}$ alloy exhibits one-step phase transformation on both heating and cooling process. The microstructure of the $\mathrm{Ni}_{50} \mathrm{Ti}_{47} \mathrm{Fe}_{2} \mathrm{Nd}_{1}$ alloy consists of NiTi B2 parent phase, $\mathrm{NiTi}_{2}$ phase and $\mathrm{NiNd}_{3}$ phase. The lattice of $\mathrm{Ni}_{50} \mathrm{Ti}_{47} \mathrm{Fe}_{2} \mathrm{Nd}_{1}$ is $\mathrm{a}=0.3035 \mathrm{~nm}$. 


\section{REFERENCES}

[1] K. Otsuka, and X. Ren, Recent Developments in the Research of Shape Memory Alloys, (1999), Intermetallics, vol. 7(5), pp. 511-528.

[2] J. G. Wang, F. S. Liu, J. M. Cao, The Microstructure and Thermomechanical Behaviour of Ti50Ni47Fe2.5Nd0.5 shape memory alloys, (2010), Materials Science and Engineering, A. vol. 527, pp. 6200-6204.

[3] J. Khalil-Allafi, W. W. Schmahl, M. Wagner, H. Sitepu, D. M. Toebbens, G. Eggeler, The Influence of Temperature on Lattice Parameters of Coexisting Phases in NiTi Shape Memory Alloys - a Neutron Diffraction Study. (2004), Materials Science and Engineering, A. vol 378, pp. 161-164.

[4] J. Q. Liu, Y. H. Zhuang, Y. Q. Hu, (2004), "The 773K Isothermal Section of the Ternary Phase Diagram of the Nd-Ni-Ti," J. Alloy Compd., vol. 368 (1-2), pp. 180-181. 